This is the submitted version of the following article, which has been published in Area 2018, 50(1), 74-82. The final form at http://onlinelibrary.wiley.com/doi/10.1111/area.12352/full.

Riikka Korkiamäki and Kirsi Pauliina Kallio

\title{
Experiencing and practising inclusion through friendships
}

\section{Abstract}

The late modern change in young people's community life has meant moving from traditional, place-based communities towards more fluid and situational contexts of belonging. These youth-initiated attachments often build upon amiable relationships that fall under the umbrella of 'friendship'. This article analyses Finnish early youths' friendship narratives that were produced by sequential participatory methods. It introduces the dimensional and flexible spaces created in and through the participants' friendships. These indicate relational spheres of actual and imagined activities where young people engage with people and places important to them. As a result, the article firstly shows how young people together with their peers develop committed ties of belonging that reach beyond physical connection, and how these ties constitute experiential spatial attachments. Secondly, it is demonstrated how they also make friends with kin and non-kin adults and how these intergenerational friendships expand the variety of inclusionary spaces available to them. The findings provide alternative insights into young people's experiences and the practices of social and spatial inclusion. We hope they help to develop cross-generational inclusionary policies that acknowledge youths' amiable relationships as important potential in their lived communities.

Keywords: friendships, young people, spatial belonging, inclusion, lived world 


\section{Experiencing and practicing inclusion through friendship}

\section{Introduction}

Physical location may never fully lose its significance in the establishment of lived communities. Yet in the contemporary world, belonging unfolds in various spatial dimensions, which makes communal life less fixed in place. While this apparent change has been demonstrated across the social sciences (e.g. Anderson 1991; Day 2006; Holloway and Valentine 2000), children and young people's social and political inclusion is still often imagined in traditional ways: manifesting itself in biological bonds, regionally limited relationships, territorially bound communities and formally defined participation (Kallio, Häkli and Bäcklund 2015; Korkiamäki and Kallio 2013; Smith et al. 2005; Wood 2012).

In this paper, we join the critical voices that highlight the implicit power relations and inequalities that the territorially based and adult-led understandings of youth inclusion involve. Like Percy-Smith (2010), Wood (2012) and O’Toole (2016), among others, have argued, institutionalised participation - typically manifested in student committees and youth councils - tends to leave young people's personal views of inclusion and communal life without due recognition. The normative expectations for youth to participate in the policies and institutional practices of states and municipalities easily set aside the experiences and knowledge that the youth at large possess, thus constricting participation into representative acts of the few. This is alienating and excluding for many youths and may cause experiences of disrespect and marginalisation.

Instead of policies and formal practices, most young people seek for and make use of inclusionary connections in informal situations and mundane communities that 
allow the expression and enactment of self-determination and solidarity (Bushin and White 2010; Cope 2008; Kallio 2016a; Trell and van Hoven 2016). Recent research on children's and young people's geographies has identified such communities as contexts of emotional and embodied politics (Beazley and Miller 2016; Blazek and WindramGeddes 2013; Cele 2013). Hence, a shift of emphasis in youth inclusion discourse seems to be taking place from 'Political' systems towards more personal and mundane 'politics' (Kallio and Häkli 2011; Percy-Smith 2016; O’Toole 2016; Skelton 2010). As a contribution to these discussions, this paper highlights that the communities young people find to be inclusive are not necessarily - or primarily - topographically formed but build on various kinds of socio-spatial connections. This, we believe, has important implications to early youths' participation motives and practices.

To present an example of where young people experience and practice inclusion spontaneously and, as part of these self-imposed activities, challenge territorial forms of belonging, we take up early youths' friendships. Here we follow Ann Bartos $(2013,21)$ who suggests that children's and young people's community life becomes intelligible through social relationships, and friendships in particular, as their lived environments are primarily defined by friendly relations (also Korkiamäki and Kallio 2013). By studying friendships we take part in developing an alternative approach to young people's mundane political worlds, which, among other things, challenges the spatial and cultural platitudes (Vanderbeck and Dunkley 2003; Wiesel and Bigby 2014). The approach portrays youth not only as active players in their everyday communities, but also as creators of inclusionary and exclusionary spaces for themselves and others (cf. Habashi and Worley 2008; Trell and van Hoven 2016).

\section{Young people's friendships and their mundane politics}


Bunnell and colleagues $(2012,498)$, in their seminal paper on the geographies of friendship, argue that in human geographical research 'friendship(s) are implied and sometimes even mentioned, but friendship itself is rarely conceptually or analytically central'. Concurrently, increasing awareness of the changing forms of belonging and inclusion has started to draw scholarly attention to voluntary affiliations. Along with the sociologists of 'new social ties', geographers have delineated how the dynamic processes of social support, care and socialisation are shifting from traditional environments to chosen and self-defined intimacies like friendships (Bowlby 2011; Chambers 2006; Rogers and Weller 2013; Valentine 2008). The expanding literature on emotional geographies has further introduced how embodied experiences, micropolitics and the intersubjective constitution of everyday environments evolve in the interplay of peer, familial and institutional relations (e.g. Aitken 2014; Beazley and Miller 2016; Blazek and Windram-Geddes 2013; Cele 2013; Harker 2010; Holt et al. 2013).

Friendships build important communalities particularly among young people who often define friends as the most important people in their lives. This has been recognised in geographical research on young people's friendships and peer relationships (for a review, see e.g. Blazek 2011). These studies typically concentrate on social relations within territorial communities, such as neighbourhoods (Aitken 2014; Beazley and Miller 2016; Blazek 2011), cities or towns (Bartos 2013; Cele 2013; Harker 2010) and schools (Thomas 2011; Wood 2012), but also network-based friendships, maintained particularly through virtual communication, have received growing attention (e.g. Tuukkanen et al. 2013; Valentine and Holloway 2002). Our paper adds a new perspective to young people's geographies of friendship by taking friendship as an analytical starting point and exploring the relational socio-spatial realms that the 'friendly geographies' create and make use of. 
Earlier research has importantly shown how friendships may provide support, trust and reliance within the cultural autonomy that young people achieve through peer relations (Blazek 2011). It has become explicit that within their self-defined communities, youths are able to constitute socio-spatial realms for their own use and habitually re-define the use and meaning of public and semi-public venues (e.g. Cele 2013). Geographers have notably revealed 'how everyday spatialities are fundamental for children's practices of friendship and how developing friendships is closely connected to children's contestations and negotiations over space' (Blazek 2011, 288). Therefore, while friendship is an important element in bringing people together, it may also bring about dissociations and create boundaries between individuals and groups.

As a flip side to support, trust and togetherness, the collective elements among friends are often played out by distinctive spatial, corporal and verbal practices that may build tight communities that shut out 'the others' or create buffer zones between 'best friends' and 'just friends' (e.g. Thomas 2011). Established social structures of power, such as class, ethnicity, gender and age allow distinct possibilities and dispositions to different people, and the inclusionary and exclusionary practices of friendship may further strengthen inequalities (Blazek 2011; Goodwin and Kyratzis 2007; Thomas 2011). Yet this does not mean that friendships are not able to build unexpected connections between apparently distant and distinct individuals and groups, or constitute empowering communities where young people may confront and resist experienced inequalities (Dyson 2010; Walsh 2007).

Moreover, friendships are not only about children's and young people's mutual affection and sympathy, or disputes within peer groups. A body of research has indicated that friendly relationships are embedded in young people's mundane political realities, crossing the borders between private and public and bringing together actors 
from various generational positions (Aitken 2014; Beazley and Miller 2016; Kallio and Häkli 2011; Jeffrey 2012). This includes informal political socialisation among friends and their close communities (Habashi and Worley 2008; Kallio 2014a, 2016b; Manning 2014), as well as the development of 'sense of belonging' and identities which often draws upon similarities and differences that friendships foster (Cele 2013; Korkiamäki 2013).

As mundane political relationships, friendships create solidarities between people and places, which in turn manifest themselves in the choices and practices of friendship (Bartos 2013; Tucker 2003). This reveals the 'social and political embeddedness of friendship' (Dyson 2010, 484) and the 'deeply social nature of young people's (political) agency' (Jeffrey 2012). Hence, we posit our attention on how amiable relationships create inclusive (and exclusive) spaces for young people and their ‘significant others' (Taylor 1994; also Kallio 2016a). This approach, as Devere and Smith $(2010,341)$ suggest, 'will help to illuminate reciprocal horizontal relations that can transform our view of the political' and, we add, has the potential to provide valuable insights for developing better policies and practices of youth inclusion.

\section{Studying friendly inclusion}

This paper draws on recent interdisciplinary research projects where participation and inclusion among early youth were explored in Finland ${ }^{1}$ (for previous results see

\footnotetext{
${ }^{1}$ The first project 'Preventing children's marginalisation through place-based participation' (SA134949) was carried out by Jouni Häkli, Kirsi Pauliina Kallio, Pia Bäcklund and Elina Stenvall. In the second project 'Early recognition in curbing the marginalization risk of children and youth' (SA264436), where Riikka Korkiamäki joined the research group, the empirical materials collected in the first project were further analysed.
} 
Bäcklund et al. 2014; Kallio 2014a, 2014b, 2016a, 2016b, 2016c; Kallio et al. 2015; Korkiamäki 2014, 2016; Korkiamäki and Kallio 2013). A part of the study was carried out with young people in primary schools (11-12 year-old participants, $n=74)$ and secondary schools (15-16 year-old participants, $\mathrm{n}=55)$ and involved two months of fieldwork. The majority of participants, including equally girls and boys, came from relatively well-off middle-class families, and their ethnic background was mainly Finnish. The analysed materials include interviews, child and youth created maps, written stories and drawings. The analysis presented in this paper traces inclusion from emotional relationships and manifestations related to sense of belonging, which acknowledges political agency as attitudes and activities springing from the everyday practices of social life (for theoretical background, see Häkli and Kallio 2014; Kallio 2007; Kallio and Häkli 2011).

The fieldwork began with a mapping exercise where the participants were asked to colour pleasant (with green), unpleasant (red) or otherwise meaningful (yellow) places on differently scaled mapping platforms (Neighbourhood, City, Region, Finland, Europe and the World). These markings were then discussed in open-ended and informal individual interviews. Following this, the participants could complete their stories by writing short essays and/or producing drawings. In select cases, a second round of in-depth interviews was performed. In a critical ethnographic spirit, we regard these materials as 'partial truths' affected by the situatedness of knowledge and the positionality of the researchers and the participants (Rose 1997; for details on research ethics see Kallio 2016c).

During the preliminary analysis, the 'geographies of friendship', as introduced by Bunnell, Yea, Peak, Skelton and Smith (2012), emerged from the research materials. We have hence analysed the participants' communal lives, first, to identify where the 
friendly relations of Finnish early youths unfold and how they establish their friendships (Kallio 2016a, 2016c; Korkiamäki 2016; Korkiamäki and Kallio 2013), and then, to explore how young people identify, uphold and create inclusive communities through experiencing and practicing friendship with their coevals and intergenerationally. This study brings together our research on two specific themes: young people's friendships (Korkiamäki 2011, 2013, 2014, 2016) and youthful political agency (Kallio 2007, 2014b, 2016a; Kallio and Häkli 2011).

As a starting point for the analysis presented in this paper, we identified the participants' friendship narratives by paying attention to how 'friends' and 'friendships' were discussed. Also the more implicit accounts of attachment, trust, alliance, acceptance, social support, reciprocity, shared interests, sense of community and spending time together intensively and frequently were investigated (cf. Bowlby 2011; also Korkiamäki and Kallio 2013). In the second phase, we studied the spatial dimensions (locations, distances, routes, networks, place attachments, reach and scope of activities) of these social relations. Thirdly, by means of in-depth reading and qualitative content analysis, we analysed the connections that the participants had narratively constructed between the places important to their friendships, the people involved in their friend-lives, and places and people that at first did not seem related.

\section{Locating and dislocating the friendly geographies of inclusion}

During the fieldwork, all participants mentioned a friend or friends, although also accounts on missing them were expressed. The discussions often started from the greencoloured spots that they had marked on the mapping platforms. These markings appointed homes of friends or places where they meet up and do things together. The 
ensuing chats about the markings, however, reached beyond the cartography of the maps, revealing relational friendly geographies.

Friendships were usually discussed with deeply emotional tones, and they unfolded through varying practices that differed by intensity, stability, spatiality, temporality and affection (cf. Cotterell 2007; Cele 2013). As we engaged this diversity in the analysis, we found that friend-like relations - with peers and adults - generated inclusive environments that crossed the borders of age groups, families, schools, neighbourhoods, towns, states and regions.

\section{Establishing belonging in peer communities}

As illustrated by earlier research (e.g. Aitken 2014; Blazek 2015; Valentine and Holloway 2002), young people come together and relate with their peers in a variety of sites. While doing that, they experience territories, develop spatial belonging and give new meanings to places and environments with their same-age friends. 11-year-old Samuel gives an example of how this may happen (also Korkiamäki and Kallio 2013, 21):

(I put Russia in green) because we did a school task on it with Kasper (a friend) (...) and the fell Saana, we climbed there (with a friend), it was fun (...) and in Oulu we had fun, and Kuopio is fun, too, one of my class mates moved there. And here's my friend's summer cottage, and in Pori we had fun, and in Sastamala (...) there's another cottage. In Forssa we stayed overnight, and we swam and did all the fun stuff.

As part of the interview, Samuel introduces his 'cartography of friendship' by going through his preferred locations in Finland and taking up one of the neighbouring 
countries. He links the spatial attachments that he mentions with positive emotions experienced in friendships, which was typical for the youths in the study. Many of the participants portrayed friendships as spatially embedded emotional relations that fostered affection regarding certain neighbourhoods, regions, towns and states (Korkiamäki and Kallio 2013). A deeper look, however, reveals that such views do not require a personal connection with the physical location but can be developed from the distance as well. As Samuel's account on Russia and Kuopio illustrates, shared interests and practices with - or even the experiences and memories of $-\mathrm{a}$ friend can bring spatial entities to life in one's experience-based lived world. Furthermore, as we traced the connections between such locations, the territorial spatial ties started to wane. Soila, 15, demonstrates (also Korkiamäki and Kallio 2013, 27):

Soila: Most of my friends live outside of Helsinki.

Interviewer: Okay, where have you met them?

Soila: Mostly on the internet, or downtown with some other friends (...) and I've been to Tampere with (friends) and then we've organised a couple of meetings in Helsinki (...) but I have many of my friends in Oulu, it's like a group of our own there. I'm going back there again during the autumn break.

Interviewer: And those you've met on the internet, as well?

Soila: Yeah or well, just one of them, and then I got to know her friends (...) and then from there it's like spread a bit broader and (...) they are my closest (friends), something I really lookforward to, and I just so much always want to go there. 
Soila's explanation of the green spots on her map of Finland includes practicing friendship in three cities: her hometown Helsinki, and Tampere and Oulu that lie about $160 \mathrm{~km}$ and $550 \mathrm{~km}$ northwards. While her friends living in Oulu first became part of her world through rather random encounters, these friendships have later expanded through face-to-face and social media networks and developed into a relational space of belonging. At the time of the fieldwork, Soila maintained them primarily through mobile technology that allowed communication regardless of the friends' whereabouts. Since then - presuming that the plans she told about came true - some of her friends have moved to other places for studies. We assume that, if they have continued to keep contact, her 'cartography of friendships' looks quite different today. Experientially, however, the community of friends has just taken a new shape in her lived world (cf. Kallio 2016a).

Soila's attachment to Oulu was created through friendly connections that generated emotional experiences of social belonging, rather than fondness of the physical town. Moreover, this circle of friends offered her a way out of being a bullied girl, a social position she was experiencing in her school (in Helsinki). By establishing new relationships beyond the school, neighbourhood and city Soila has adopted a subject position that locality does not circumscribe (Korkiamäki and Kallio 2013, 27). Such empowerment illustrates how friend-initiated engagements may apparently influence the wellbeing of youths and support their social inclusion (cf. Cotterell 2007). At the same time, however, Soila's story reminds about the exclusionary dimensions of friendships that may enforce inequalities in physically fixed places like schools (Blazek 2015; Thomas 2011).

Another example of friendly place attachments is provided by Mirella, 11, who coloured various countries and cities green on the world map platform (Figure 1). In the 
interview, she connected the markings with emotions and activities that actualise with her friends. For example, she introduced the US and Madagascar as significant mediated sites based on the TV series Glee and the movie Madagascar that she is a fan of with her best friends. They are also collectors of 'Pullip Dolls' from South Korea, which explains the Korea marking as well as another marking on the city of Rovaniemi (in her country map). The greening of China and Japan relates to a forthcoming possibility to visit the region with her Girl Scout friends. The rest of the markings in Figure 1 bring up other issues and relationships important in her life (including intergenerational friendly ties).

Mirella's portrayal of the world illustrates how friendships build experienced realities where amiability defines spatial ties and creates inclusive connections between people and places. The Pullip Doll hobby, for instance, has made her aware of South Korean popular culture and has associated her and her friends with a global community

\section{Figure 1: Mirella's lived world of meaningful places}

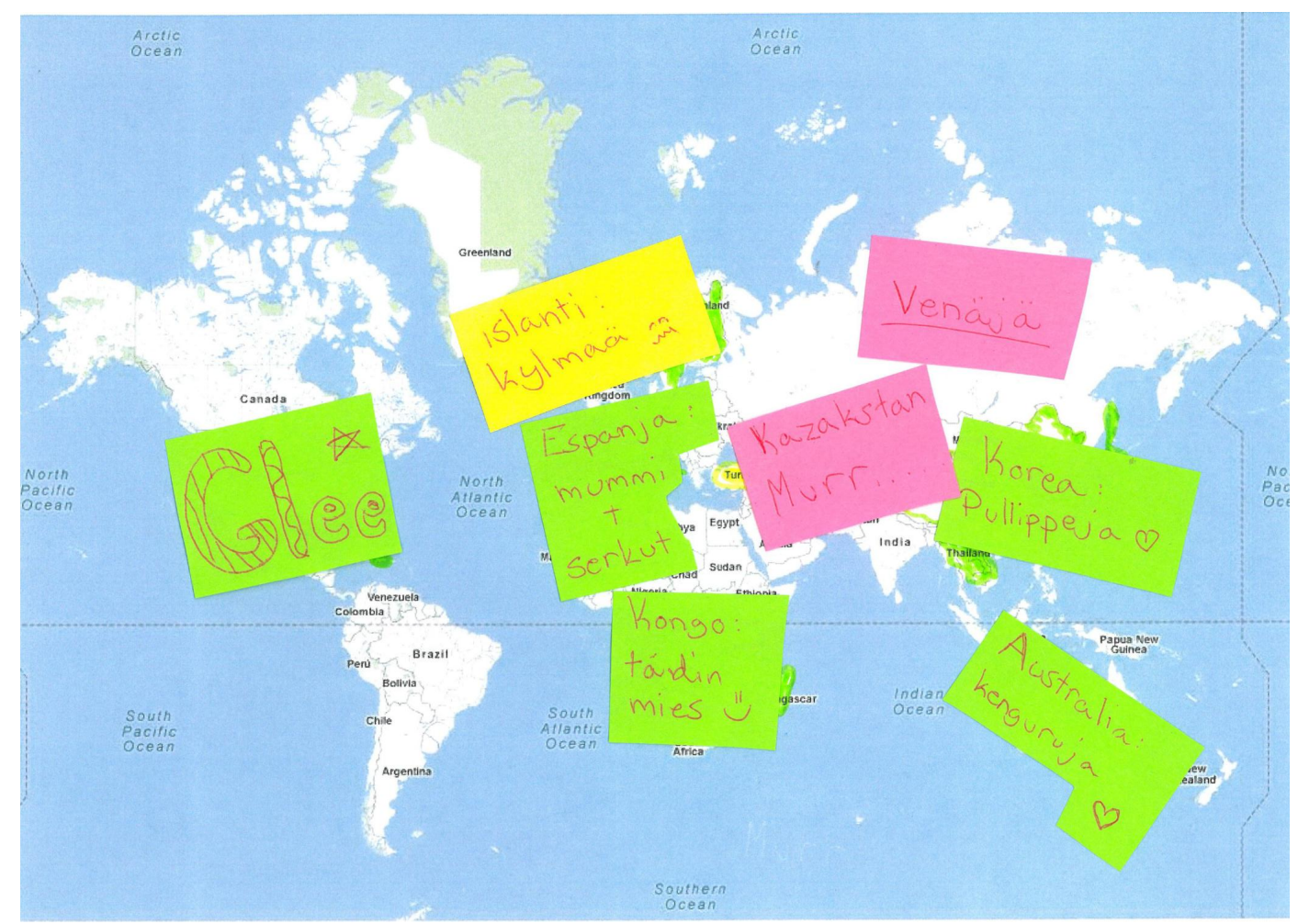


of doll collectors. They meet regularly through social media to share carefully staged pictures of their dolls, buy and sell dolls and accessories and give tips related to the hobby. Moreover, this transnationally shared interest has raised the girls' interest to visit Rovaniemi, a major city in Lapland, as the only Finnish Pullip Doll shop is located there.

Extending inclusionary spaces with grown-up friends

As Mirella, Samuel and Soila illustrated above, emotional experiences of belonging among peers may lead to surprising spatial attachments, and to social, cultural and physical connectedness. However, when going through the participants' elaborations on the relationships they had marked on their maps, we noticed that 'friends' referred to people from many generational positions. Family members - siblings, parents, cousins, grandparents, aunts and uncles - were sometimes introduced as friends rather than as relatives. In addition, friendships seemed to have developed between youth and non-kin adults such as godparents, neighbours, hobby instructors and friends' parents (also Kallio 2016a, 2016c). To give a few examples, Eveliina, 15, named her mother as her best friend, and Leena, 11, told that her aunt is 'just cool like friends'. In several cases, friendships initially established by parents provided long-lasting amiable situations to all family members. Laura, 15, describes this as follows:

This is Olga's home, she's one of my best friends. She's like been my friend, we've been together the longest, through our parents. The families are still friends too. 
Providing a contrary perspective, Miko, 15, shared in the interview how his peer relationship have succeeded in mobilising friendships between his parents and the parents of his close friend (also Korkiamäki and Kallio 2013, 25). The boys' intense relationship has led to a longstanding liaison between the two families, including joint travels and gatherings. Thus, spending time together as families and friends opens up new opportunities for creating spatial attachments, learning about the world together and feeling included beyond family or peer group. This kind of intergenerational social inclusion seemed particularly meaningful to Miko who felt like an outsider in his local peer communities.

Further, Roosa, 15, had made friends with her mother's colleague. With her adult friend, she is able to enter places that, otherwise, are inaccessible to her. Their memorable joint visits to the adult friend's workplace, horse stables and other 'adult areas' inspired her to colour the places on her map and share these connections in the interview. Roosa's account thus shows how friendships may exceed generational spatial divisions that normally allocate urban environments to children (e.g. playgrounds and family restaurants), youth (e.g. skate parks and fast-food restaurants), adults (e.g. boulevards and fine-dining restaurants) and the elderly (e.g. accessible parks and canteens) (cf. Kallio 2016a). Similarly, Saana, 15, through a 'friendly grandmother', has access to places that are not part of her familial or peer life:

Saana: Iforgot to mark my grandparents 'cause it's not the house where they live that's important, but it's them. Interviewer: Yeah, the people. And the grandma you mentioned, is she from your mum's or dad's side? 
Saana: Actually, she's neither but more like --- well my mum's parents are divorced and she kind of belongs to my mum's mum's...

Interviewer: (...) Could you tell us more about these people who are a bit older, who are clearly quite important to you, who you spend a lot of time with? How is it different from younger friends and family?

Saana: Well it's very different. From them I get hints and tips that come from their experience, if I ask what to do, and they understand since they've gone through it. Grandparents, they can be less involved if something is going on in my family.

Interviewer: So who would you talk with about that kind of stuff?

Saana: With my grandma, the one I forgot to mark. I feel really close to her and can talk with her about these kinds of things. We also play with her dog and take him out, go to the ballet and coffee shops in town, and things like that.

Ineterviwer: Doing things you both enjoy?

Saana: Yeah, and things I don't do with my other friends.

In Saana's lived world, the elderly members of her family have a particular place. She engages actively with them as a person and not merely as a grandchild. When talking about her grandparents she brought up generational aspects in a rather traditional sense, but in the case of her 'extra-grandmother' she instead stresses equality. She expresses how they share personal concerns and do special things together, including dwelling in public space and engaging in cultural activities, thus crossing generational boundaries that are typically seen as merely familial. In this way, they are constituting an inclusive world where age and social positions are not categorical. 
Along similar lines, several other participants described how their grandparents and other kin and non-kin adult friends participate in their hobbies and school activities, thus becoming part of the youth communities and mundane milieus. For instance, Juhani, 15, told how his parents had recently taken part in a TV-night with his peers. Sara's, 11, neighbours organise parties and events with the local kids, and the neighbourhood where Johannes, 15 , lives meet regularly in soccer activities:

There's adults, too, we play against them. I used to play in a team a long time ago, but I think it's more fun this way, playing with these friends.

Above, some of our participants have demonstrated that, as friendships blend in with familial life and adults socialise with kids, kith and kin merge into socially established, inclusionary intergenerational communities (cf. Aitken 2014; Harker 2010; Mason and Tipper 2008). By sharing their 'amiable everyday', young people and adults create intergenerational interplays where new opportunities may emerge from anyone's initiative. To those involved, these kinds of activities affect the meanings of neighbourhood, home, school, town, workplace, ballet theatre, holiday resort and other mundane environments, allowing inclusive communities of living together to develop within and beyond place-based communities.

\section{Towards friend-inclusive policymaking}

In this article, we have introduced inclusion as a communal element experienced and practised by early youths through their friendships, involving active peer and intergenerational relations alike. By their maps and in the interviews the Finnish young people who participated in our research demonstrated how their friendships are socio- 
spatially fluid and flexible rather than merely place-based and bound by fixed categories, which takes further previous findings from the research that concerns youthful political agency and belonging (e.g. Kallio 2016c; Häkli and Kallio 2014; Kallio et al. 2015). The analysis then suggests that the transformable, mobile, shifting and situational relations where inclusion is claimed by young individuals together with their 'significant others' unfold in various spatial dimensions. Hence, we propose that the multidimensional communities where young people dwell, grow up, and develop ideas about themselves and others form relational friendly geographies that are fundamentally important contexts of youth inclusion. The connections young people create by means of friendship give new and interesting insight into how young people may find themselves included in communities and societies.

Adding to the traditional approach on young people's friendships as peer relations, our analysis shows that youth-initiated mundane communities often cross with those of adults (cf. Goodwin and Kyratzis 2007). Moreover, it suggests that friendly youth-adult relationships lead to different kinds of spatial attachments and inclusionary relations compared to those created solely with peers. Whereas peer groups tend to connect people and places into socially and emotionally tight communities, the connections formed in intergenerational friendships are often more porous in nature, thus opening up opportunities to create alternative social relations and activities. Both of these forms of friendship involve important inclusionary potential, as young people are active participants in the communities and relationships they define as 'friendly'.

The dynamic encounters among young people and between youths and people from other generational positions gradually establish experienced belonging and feed into broader spatial and cultural involvement. The way this happens is not, however, straightforward. The youths in this study emphasised the spatial attachments of their 
friendships as socially defined, meaning that the people and places important to them may reside near or far, and connect in unexpected ways (cf. Kallio 2016c; Häkli and Kallio 2014; Kallio et al. 2015). Alongside personal experiences, also second-hand understandings, collective memories, learned knowledge and media seem to play an important role in the formation of socio-spatial relations. This plurality calls for further empirical exploration in geographies of friendship that unfold in various ways in different parts of the world. While we regret that our analysis is limited to the experiences of middle-class Western youths, who have particularly good opportunities for building friendships beyond their immediate surroundings, we believe that friendships are spatially multifaceted everywhere and that they offer contexts of inclusion not solely bound by local communities and regional framings.

As a sum up, we underline that friendships are not just about one-to-one and ingroup interaction, but have a central role in the everyday politics where personal and common concerns meet. We propose that recognising the potential of friendships in creating belonging, boundary crossings and inclusion offers new opportunities for participatory policy making in the contemporary world of increasingly complex communalities (cf. Bowlby 2011; Bunnell et al. 2012). Youth inclusion could be promoted by, first, realising young people's belonging as socially established and not primarily territorially based and, second, acknowledging their capacities to create inclusionary communities in mundane (political) environments together with their 'significant others' from various generational positions. Furthermore, while friendships are crucial drivers in informal and 'tacit' inclusion, we see their potential also in formal inclusionary processes (see e.g. O'Toole 2016; Percy-Smith 2016; Trell and van Hoven 2016). Instead of solely place-based organisation, participation could begin from friend- 
based affiliations that bring to the fore grassroots issues and bottom-up experiences identified and shared by young people in their friendly worlds.

\section{Acknowledgements}

We wish to thank our colleagues at the Space and Political Agency Research Group (SPARG), University of Tampere, and particularly Pia Bäcklund, Jouni Häkli and Elina Stenvall for their irreplaceable participation in the projects. We also thank the editor and the two anonymous reviewers for their valuable comments. The writing of this paper was supported by the Academy of Finland under Grants and SA264436 and SA285592.

\section{References}

Aitken SC 2014 The Ethnopoetics of Space and Transformation: Young People's Engagement, Activism and Aesthetics Ashgate, Farnham

Anderson B 1991 Imagined Communities: Reflections on the Origin and Spread of Nationalism Verso, London

Bäcklund P, Kallio KP and Häkli J 2014 Residents, customers or citizens? Tracing the idea of youthful participation in the context of administrative reforms in Finnish public administration Planning Theory and Practice 15 311-327

Bartos A 2013 Friendship and environmental politics in childhood Space and Polity 17 $17-32$

Beazley H and Miller M 2016 The art of not been governed: street children and youth in Siem Reap, Cambodia in Kallio K P and Mills $\mathbf{S}$ eds Politics, Citizenship and Rights Springer, Singapore 263-289

Blazek M 2011 Place, children's friendships, and the formation of gender identities in a Slovak urban neighbourhood Children's Geographies 9 285-302 
Blazek M 2015 Rematerialising children's agency: Everyday practices in a postsocialist estate Policy Press, Bristol

Blazek M and Windram-Geddes M 2013 Special issue on children's emotional geographies Emotion, Space and Society 9

Bowlby S 2011 Friendship, co-presence and care: neglected spaces Social \& Cultural Geography 12 605-622

Bunnell T, Yea S, Peake L, Skelton T and Smith M 2012 Geographies of friendships Progress in Human Geography 36 490-507

Bushin N and White A 2010 Migration politics in Ireland: exploring the impacts on young people's geographies Area 42 170-180

Cele S 2013 Performing the political through public space: teenage girls' everyday use of a City Park Space and Polity 17 74-87

Chambers D 2006 New Social Ties: Contemporary Connections in a Fragmented Society Palgrave Macmillan, London.

Cope M 2008 Patchwork neighborhood: children's urban geographies in Buffalo, New York Environment and Planning A 40 2845-2863

Cotterell J 2007 Social Networks in Youth and Adolescence Routledge, London Day G 2006 Community and Everyday Life Routledge, London

Devere H and Smith G 2010 Friendship and Politics Political Studies Review 8 341356

Dyson J 2010 Friendship in practice: girls' work in the Indian Himalayas American Ethnologist 37 482-498

Goodwin MH and Kyratzis A 2007 Children socializing children: practices of negotiating the social order among peers Research on Language and Social Interaction 40 279-289 
Habashi J and Worley J 2008 Child geopolitical agency: a mixed methods case study Journal of Mixed Methods Research 3 42-63

Harker C 2010 On (not) forgetting families: family spaces and spacings in Birzeit, Palestine Environment and Planning A 42 2624-2639

Holloway S and Valentine G 2000 Spatiality and the 'new' social studies of childhood Sociology 34 763-783

Holt L, Bowlby S and Lea J 2013 Emotions and the habitus: young people with socioemotional differences (re)producing social, emotional and cultural capital in family and leisure space-times Emotion, Space and Society $933-41$

Häkli J and Kallio KP 2014 Subject, Action and Polis Theorizing Political Agency Progress in Human Geography 38 181-200

Jeffrey G 2012 Geographies of children and youth II: Global youth agency Progress in Human Geography 36 245-253

Kallio KP 2007 Performative bodies, tactical agents and political selves Rethinking the political geographies of childhood Space and Polity 11 121-136

Kallio KP 2014a Rethinking spatial socialization as a dynamic and relational process of political becoming Global Studies of Childhood 4 210-223

Kallio KP 2014b Intergenerational recognition as political practice in Vanderbeck $\mathbf{R}$ and Worth N eds Intergenerational Space Routledge, London 139-154

Kallio KP 2016a Shaping subjects in everyday encounters: Intergenerational recognition in intersubjective socialisation Environment and Planning D: Society and Space 35 88-106

Kallio KP 2016b Becoming geopolitical in the everyday world in Benwell M and Hopkins P eds Children, Young People and Critical Geopolitics Aldershot, Ashgate $169-186$ 
Kallio KP 2016c Living together in the topological home Space and Culture 19 373389

Kallio KP and Häkli J 2011 Are there politics in childhood? Space and Polity 15 2134

Kallio KP, Häkli J and Bäcklund P 2015 Lived citizenship as the locus of political agency in participatory policy Citizenship Studies 19 101-119

Korkiamäki R 2011 Support and Control among Friends and Special Friends: Peer Group's Social Resources as Emotional and Moral performances amidst Teenagers Children \& Society 25 104-114

Korkiamäki R 2013 Kaveria ei jätetä! Sosiaalinen pääoma nuorten vertaissuhteissa [No Friend Left Behind! Social Capital and Young People's Peer Relations] Tampere University Press and Finnish Youth Research Society, Tampere

Korkiamäki R 2014 Rethinking Loneliness — A Qualitative Study about Adolescents' Experiences of Being an Outsider in Peer Group Open Journal of Depression 3 125-135 Korkiamäki R 2016 Friendship as Potential? Recognition of Teenagers’ Peer Relationships at School Open Journal of Social Sciences 4 34-43

Korkiamäki R and Kallio KP 2013 Ystävyys tilallisen kiinnittymisen suuntaajana Tilateoreettisia tulkintoja lasten ja nuorten ystävyyksistä [The role of friendship in the formation of spatial attachments spatial theoretical approach to children's and young people's friendships] Alue ja ympäristö 43 16-33

Manning N 2014 The relational self and the political engagements of young adults Journal of Sociology 50 486-500

Mason J and Tipper B 2008 Being related: how children define and create kinship Childhood 15 441-460 
O’Toole T 2016 Beyond crisis narratives: changing modes and repertoires of political participation among young people in Kallio KP and Mills $\mathbf{S}$ eds Politics, Citizenship and Rights Springer, Singapore 225-242

Percy-Smith B 2010 Councils, consultations and community: rethinking the spaces for children and young people's participation Children's Geographies 8 107-122

Percy-Smith B 2016 Negotiating active citizenship: young people's participation in everyday spaces in Kallio KP and Mills $\mathbf{S}$ eds Politics, Citizenship and Rights Springer, Singapore 401-422

Rogers C and Weller S 2013 Critical Approaches to Care: Understanding Caring Relations, Identities and Cultures Routledge, Abingdon

Rose G 1997 Situating knowledges: positionality, reflexivity and other tactics Progress in Human Geography 21 305-320

Skelton T 2010 Taking young people as political actors seriously: opening the borders of political geography Area 42 145-151

Smith N, Lister R, Middleton S and Cox L 2005 Young people as real citizens: towards an inclusionary understanding of citizenship Journal of Youth Studies 8 452-53 Taylor C 1994 The politics of recognition in Gutmann A ed Multiculturalism: Examining the Politics of Recognition Princeton University Press, Princeton, NJ 25-73 Thomas M 2011 Multicultural Girlhood: Racism, Sexuality and the Conflicted Spaces of Urban Education Temple University Press, Philadelphia

Trell EM and van Hoven B 2016. Young people and citizenship in rural Estonia: an everyday perspective in Kallio KP and Mills $\mathbf{S}$ eds Politics, Citizenship and Rights Springer, Singapore 423-444

Tucker F 2003. Sameness or difference? Exploring girls' use of recreational spaces Children's Geographies 1 111-124 
Tuukkanen T, Wilska T-A, Iqbal A and Kankaanranta M 2013 Children's Social Participation in Virtual Worlds. International Journal of Virtual Communities and Social Networking 5 59-73

Valentine G 2008 The ties that bind: towards geographies of intimacy Geography Compass 2 2097-2110

Valentine G and Holloway S 2002 Cyberkids? Exploring children's identities and social networks in on-line and off-line worlds Annals of the Association of American Geographers 92 302-319

Vanderbeck R and Dunkley C 2003 Young people's narratives of rural-urban difference Children's Geographies 1 165-80

Walsh K 2007 'It got very debauched, very Dubai!' Heterosexual intimacy amongst single British expatriates Social \& Cultural Geography 8 507-533

Wiesel I and Bigby C 2014 Being recognised and becoming known: encounters between people with and without intellectual disability in the public realm Environment and Planning A 46 1754-1769

Wood B 2012 Crafted within liminal spaces: young people's everyday politics Political Geography $31337-346$ 